\title{
Antifriction and antiwear properties of an ionic liquid with fluorine-containing anion used as lubricant additive
}

\author{
D. Blanco ${ }^{\mathrm{a}^{*}}$, R. González ${ }^{\mathrm{c}, \mathrm{d}}$, J.L. Viesca ${ }^{\mathrm{a}, \mathrm{d}}$, A. Fernández-González ${ }^{\mathrm{b}}$, \\ M. Bartoloméc ${ }^{\text {A. Hernández Battez }}{ }^{\mathrm{a}, \mathrm{d}}$ \\ ${ }^{\text {a }}$ Department of Construction and Manufacturing Engineering, University of Oviedo, Asturias, Spain \\ ${ }^{\mathrm{b}}$ Department of Physical and Analytical Chemistry, University of Oviedo, Asturias, Spain \\ ${ }^{c}$ Department of Marine Science and Technology, University of Oviedo, Asturias, Spain \\ ${ }^{\mathrm{d}}$ Department of Design and Engineering, Bournemouth University, Poole, BH12 5BB, UK \\ ${ }^{(*)}$ Email: blancoadavid@uniovi.es
}

\begin{abstract}
Tribological behavior of trihexyltetradecylphosphonium bis(trifluoromethylsulfonyl) imide $\left[\mathrm{P}_{66614}\right]\left[\mathrm{NTf}_{2}\right]$ ionic liquid (IL) used as additive in a diester oil at concentrations of $0.25,0.5$ and $1 \mathrm{wt} \%$ was studied in this research. The IL solubility in the base oil was measured using the inductively coupled plasma mass spectrometry (ICP-MS) technique and corrosion analysis was done at room temperature at relative humidity of 49-77\%. Tribological tests were conducted for 30 minutes at room temperature, $15 \mathrm{~Hz}-$ frequency, $4 \mathrm{~mm}$ of stroke length, a load of $80 \mathrm{~N}$ (corresponding to $2 \mathrm{GPa}$ of maximum contact pressure) and relative humidity of $35-53 \%$. Friction coefficient was recorded during tests and the wear scar was measured by confocal microscopy. Worn surface was also analyzed by SEM, EDS and XPS.

Results showed that a saturated solution of $\left[\mathrm{P}_{66614}\right]\left[\mathrm{NTf}_{2}\right]$ in the base oil contains about $30 \mathrm{wt} \%$ of IL and corrosion activity for the highest concentration of IL (1 wt\%) was not found after a 20-day test. Although the base oil and the mixtures had similar friction behavior, $1 \mathrm{wt} \%$ sample exhibited slightly lower wear volume than the base oil. Regarding surface analysis, SEM images exhibited similar wear track width $(707-796 \mu \mathrm{m})$ and wear mechanism (adhesive) for all samples tested. In addition, the EDS spectra only showed the elements present in the steel. Finally, XPS study could not detect differences regarding iron chemical state. This mentioned similitude among the samples is consistent with the tribological behavior obtained.
\end{abstract}

Keywords: ionic liquid, friction, wear, lubricant additive

\section{Introduction}

Ionic liquids (ILs) are salts formed by the interaction between a weakly-coordinating inorganic anion and an organic cation and with melting point lower than $100^{\circ} \mathrm{C}$ [1]. Since 2001, when Ye et al. [2] published the first research on ionic liquids in Tribology, the potential incorporation of these compounds into the next generation of lubricants became an active and expanding line of research [3-6]. The remarkable performance of ILs in tribology is related to their excellent properties, which include high ionic conductivity and thermo-oxidative stability, negligible vapor pressure, low melting point and flammability and controlled miscibility with organic compounds $[7,8]$.

Early tribology research with ILs was carried out using imidazolium cations and fluorine-containing anions, especially $\left[\mathrm{BF}_{4}\right]$ and $\left[\mathrm{PF}_{6}\right][9-17]$. However, these fluorine-based anions tend to produce corrosion 
in the presence of water [18-20]. This drawback led to the incorporation of new and more stable fluorine containing anions like [FAP] [21-30] and [NTf 2$]$ [31-40]. The excellent lubricating performance of these anions is directly related to their reactivity $[13,23,26]$, inducing the formation of protective adsorbed tribofilms on metal surfaces, especially at high load conditions [6], and contributing to friction and wear reduction. In addition, the inherent low solubility of ionic liquids in traditional base oils means that polarity becomes a critical property that should be taken into account if they are to be used as lubricant additives, usually in very low concentrations or even in oil-IL emulsions [41-44]. Therefore, these compounds have been used principally as base stock in tribology research, showing great potential for this purpose $[5,13,21,45-49]$. However, replacing traditional base oils by ILs is mainly limited by their cost, so their use as neat lubricant is reduced to circumstances where there are special operating conditions [41,50-52].

In order to overcome all the limitations mentioned above, some phosphonium cation-based ILs have been reported as excellent additive candidates due to their full miscibility in non-polar hydrocarbon oils [5360]. Although some papers mentioned above have studied the tribological behavior of phosphonium ionic liquids as a lubricant additive in different base oils and material pairs, no studies have dealt with the effectiveness of using the trihexyltetradecylphosphonium bis(trifluoromethylsulfonyl) imide ionic liquid $\left(\left[\mathrm{P}_{66614}\right]\left[\mathrm{NTf}_{2}\right]\right)$ as a lubricant additive in a diester oil for steel-steel contact. Therefore, this research work analyzes the antifriction and antiwear properties of this phosphonium-cation based IL used as an additive in a diester oil at three different concentrations, keeping the phosphorous content in the mixtures below 800 ppm according to ILSAC GF-5 specifications for motor oils.

\section{Experimental details}

\subsection{Ionic liquid and base oil}

The phosphonium cation-based ionic liquid $\left[\mathrm{P}_{66614}\right]\left[\mathrm{NTf}_{2}\right]$ used as additive in this work was provided by Io-Li-Tec (Ionic Liquid Technologies GmbH). The base oil (Priolube 1936, coded as A2) was kindly supplied by CRODA. Table 1 shows the chemical properties of the fluids used. Mixtures of the base oil and $\left[\mathrm{P}_{66614}\right]\left[\mathrm{NTf}_{2}\right]$ were prepared using $0.25,0.5$ and $1 \mathrm{wt} \%$ of IL, corresponding to a phosphorus concentration of 108.5, 217 and 434 ppm, respectively. 
Table 1. Material properties.

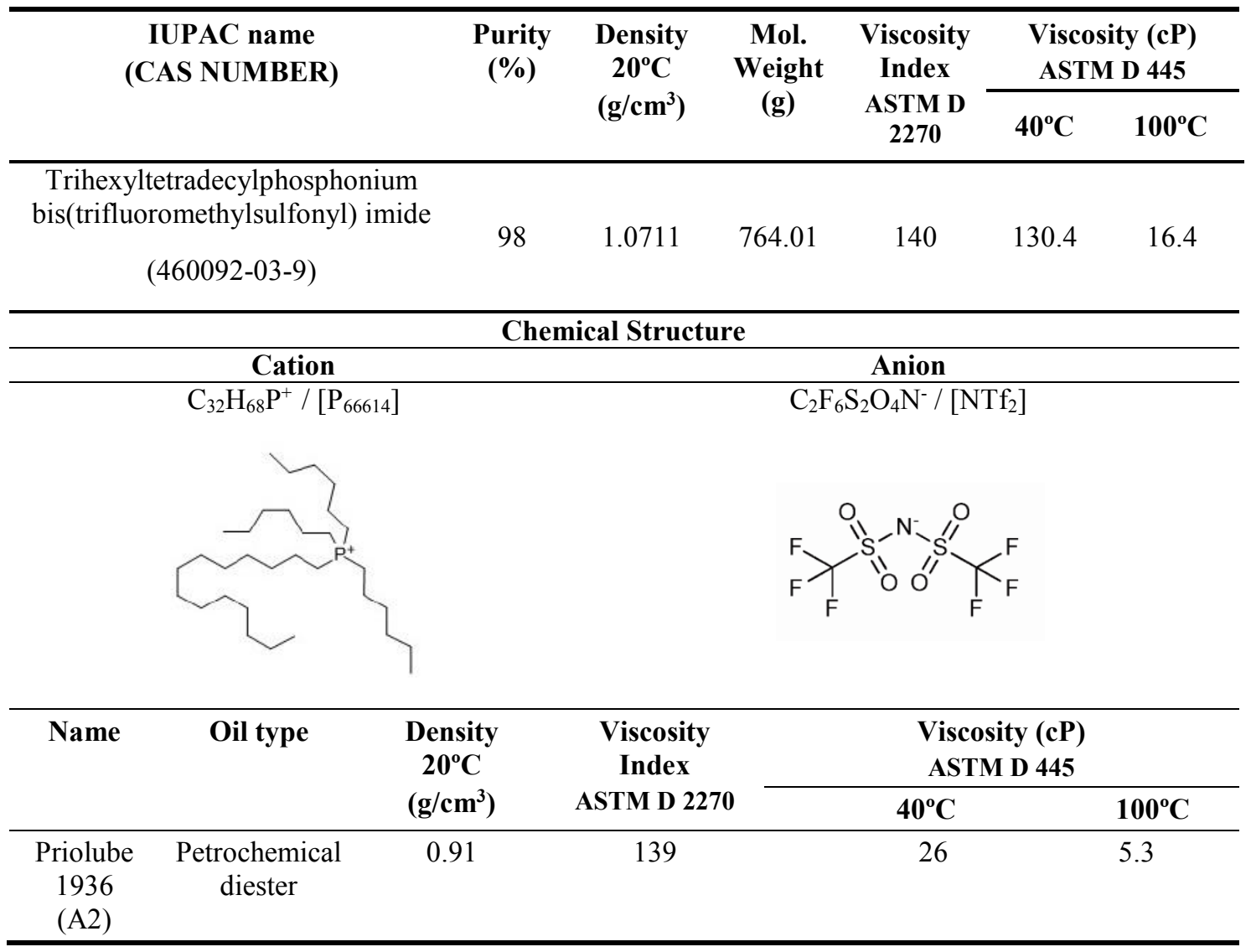

\subsection{Solubility and corrosion}

A solubility test was carried out following several steps. Firstly, the ionic liquid (about $1 \mathrm{~mL}$ ) was added to the base oil (about $2 \mathrm{~mL}$ ) and vortexed in a Labonet VX 100 vortex until saturation of the ionic liquid in the base oil was ensured (homogenous suspension). Secondly, the mixture was centrifuged at $5000 \mathrm{rpm}$ for three minutes in a Thermo electron corporation Heraeus Labofuge 200 centrifuge, discarding the densest phase (ionic liquid). Thirdly, the base oil phase (less dense) was decanted and digested with $65 \%$ $\mathrm{HNO}_{3}: 25 \% \mathrm{H}_{2} \mathrm{O}_{2} 7: 1$ mixture in a microwave oven, diluting the residue as much as necessary with the aim of analyzing it by ICP-MS. Finally, the sample was left at room temperature in the dark and the protocol was repeated from the centrifugation step after 7, 14 and 21 days.

The corrosion character of the mixtures was studied using a simple test used in a previous study [45]: a drop of the highest ionic liquid concentration blend (1\% wt.) was applied to the surface of an AISI 52100 steel disc (previously ultrasonically cleaned in heptane and air-dried) provided by PCS-Instruments and used as received (see its characteristics in Table 2). The specimen remained at room temperature for 20 days while the corrosion activity was observed. Test was conducted at $49-77 \%$ relative humidity, 
measured at different hours of each of the 20 days of corrosion test. Subsequently, the steel surfaces were

\subsection{Tribological tests}

A Bruker-UMT-3 micro-tribometer with a reciprocating ball-on-plate configuration was employed in order to study friction, wear and tribofilm formation in the contact. The upper (balls) and lower (disks) specimens used are both manufactured from AISI 52100 steel (machined from annealed rod) and were used as received from the provider (PCS-Instruments). The physical description and chemical composition of both specimens are displayed in Table 2.

Table 2. Description of the specimens used in tribological tests.

Chemical composition (\%)

\begin{tabular}{|c|c|c|c|c|c|c|}
\hline \multirow{2}{*}{ AISI 52100 } & $\mathrm{C}$ & $\mathrm{Si}$ & $\mathrm{Mn}$ & $\mathrm{Cr}$ & $\mathrm{P}$ & $\mathrm{S}$ \\
\cline { 2 - 6 } & $0.98-1.1$ & $0.15-0.30$ & $0.25-0.45$ & $1.30-1.60$ & 0.025 & 0.025 \\
\cline { 2 - 6 } & Dimensions & Hardness & Roughness (Ra) \\
\hline Balls & $9.5 \mathrm{~mm}$ diameter & $63 \mathrm{HRC}$ & $0.01 \mu \mathrm{m}$ \\
\hline \multirow{2}{*}{ Disks } & $\begin{array}{c}10 \mathrm{~mm} \text { diameter } \\
\times 3 \mathrm{~mm} \text { thick }\end{array}$ & \multicolumn{2}{|c|}{$190-210 \mathrm{HV}_{30}$} & $0.02 \mu \mathrm{m}$ \\
\hline
\end{tabular}

Friction and wear tests were performed for a period of 30 min under normal loads of $80 \mathrm{~N}$ (corresponding to mean contact pressures of $2.1 \mathrm{GPa}$ ), $4 \mathrm{~mm}$ stroke length and a frequency of $15 \mathrm{~Hz}$. Normal load was applied using a closed-loop servomechanism, and normal load and friction force were measured with the strain-gages. All tests were carried out at room temperature and 35-53\% relative humidity measured at the beginning of the test, using about $4 \mathrm{~mL}$ of mixture in each experiment to ensure fully-flooded conditions in the contact. The friction coefficient was recorded during the tests and wear volume was measured on the disk surface using confocal microscopy (Leica DCM 3D). In addition, at least three runs for each test condition were made. Specimens were cleaned with heptane in an ultrasonic bath for 5 minutes before tribological tests. Previous to the characterization of the worn surface, balls and disks were cleaned in heptane again, rinsed in ethanol and then air-dried. 


\subsection{Surface characterization}

In order to study and evaluate the interaction of the mixtures with the worn surface, scanning electron microscopy (SEM), energy dispersive spectroscopy (EDS) and X-Ray photoelectron spectroscopy (XPS) were used for all tests conducted. A JEOL-6610-LV SEM with a tungsten filament electron gun working at a $20 \mathrm{kV}$ acceleration voltage, a maximum resolution of $3.0 \mathrm{~nm}$ (high vacuum mode) from $\times 5$ to $\times 50$ 000 magnification and a secondary electron detector was used. Microanalysis equipment integrated in the microscope had an SDD detector model Xmax 50 with linear resolution of $125 \mathrm{eV}$ in $\mathrm{Mn} \mathrm{K \alpha}$ from 1 to $20000 \mathrm{cps}$ and active area of $50 \mathrm{~mm}^{2}$. The detection and quantification of elements is from atomic number 4 (Beryllium) and the ultra thin window allows detection and analysis of ultralights $(\mathrm{C}, \mathrm{N}, \mathrm{O} \ldots)$. Complete integrated software Oxford INCA allows selection of points or areas for analysis on the microscopic image. XPS measurements were made with a SPECS XR50M monochromatized source using AlK $\alpha$ as anode $(1486.7 \mathrm{eV}, 150 \mathrm{~W})$ at $45^{\circ}$ emission angle. The $3.5 \times 1 \mathrm{~mm}^{2} \mathrm{X}$-Ray spot was focused on the wear scar in every sample, with the electromagnetic lenses in high magnification mode. In these conditions, according to the spectrometer documentation, the acceptance area is expected to be $2 \times 0.7$ $\mathrm{mm}^{2}$. The binding energy was referred to the adventitious carbon at $284.6 \mathrm{eV}$ [61-63]. High resolution spectra were taken using an energy step of $0.1 \mathrm{eV}$ with a pass energy of $30 \mathrm{eV}$. The number of spectra used to determine the average was 15 for O1s, 35 for F1s and between 40 and 50 for Fe2p3/2, depending on the sample.

\section{Results and discussion}

\subsection{Solubility and corrosion tests}

Analyzing the solubility results obtained by ICP-MS, $\left[\mathrm{P}_{66614}\right]\left[\mathrm{NTf}_{2}\right]$ exhibited a concentration value close to $30 \mathrm{wt.} \%$ in the base oil after the 21 -day test, ensuring a proper solubility of the ionic liquid in the base oil for all concentrations of IL $(0.25,0.5$ and $1 \mathrm{wt} \%)$ used in the tribological tests. This solubility methodology is similar to that used by Otero et al. [49]. Table 3 illustrates corrosion activity, showing the images recorded over 20 days for the sample with the highest concentration of IL ( $1 \mathrm{wt} \%)$. This test was previously used for reporting the corrosion activity of $\left[\mathrm{P}_{66614}\right]\left[\mathrm{NTf}_{2}\right]$ as a neat sample [45]. In that case the IL caused corrosion on the steel surface. However, no signs of corrosion attack appeared in any of the four images taken $(0,168,336$ and $480 \mathrm{~h})$ during the test made in this work and the appearance of the surface remained practically constant in all cases. This fact leads us to assume that the corrosion observed 
for the neat $\left[\mathrm{P}_{66614}\right]\left[\mathrm{NTf}_{2}\right]$ could be related to the presence of water and impurities instead of the IL character. Meanwhile, the dilution effect in the oil-IL mixture could also cover up the mentioned corrosive activity. In addition, the steel surface analysis by scanning electron microscopy (SEM) and energy dispersive spectroscopy (EDS) confirmed the absence of corrosion mentioned before. Therefore, there is no problem with using this IL as an additive in a steel-steel tribological contact from a corrosion point of view.

Table 3. 20-days corrosion test.

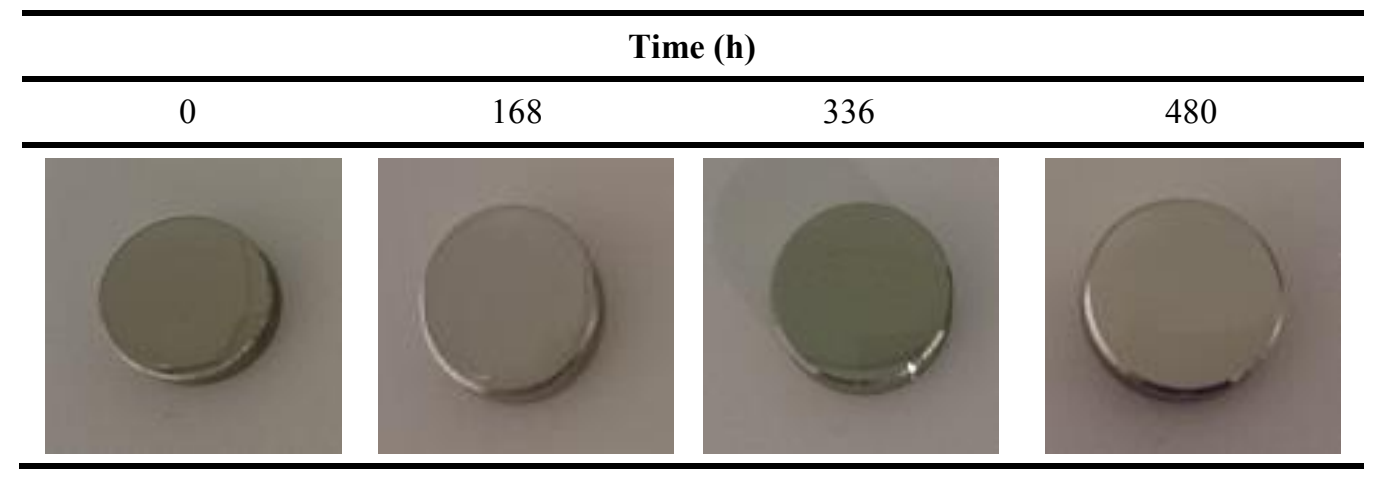

\subsection{Friction and wear}

It can be observed in Fig.1 that all ionic liquid mixtures (including base oil) had an initial friction coefficient of around 0.075 . This value remained fairly constant until the end of the test, it being difficult to establish significant differences between the four samples from a friction coefficient point of view.

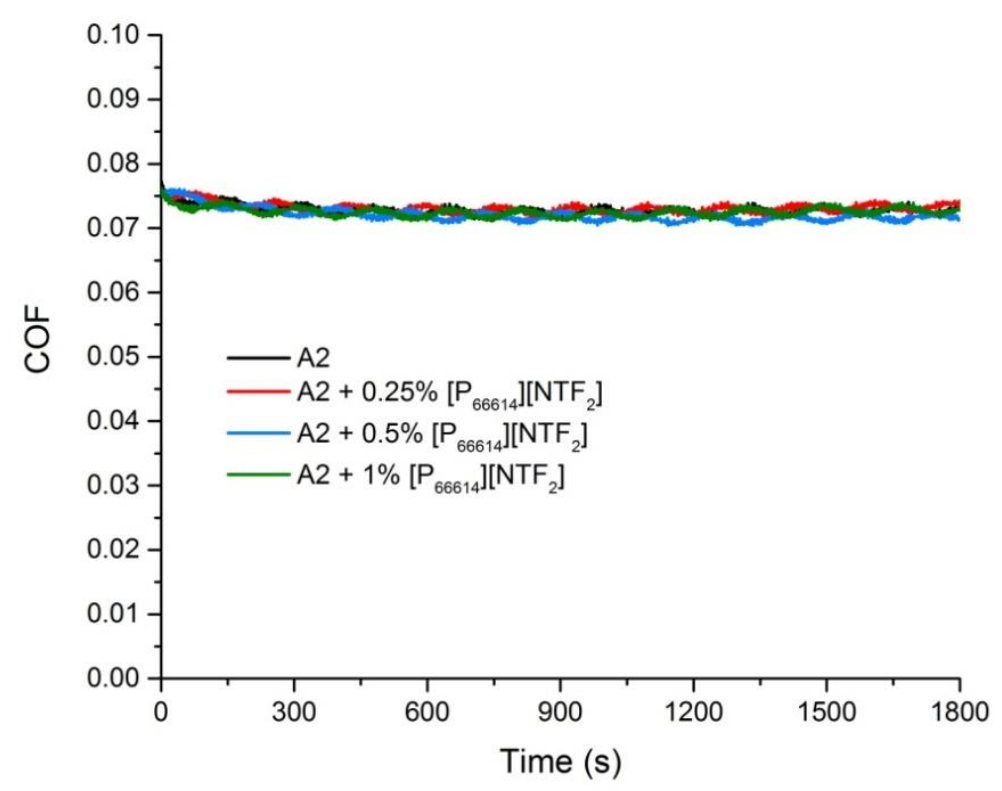

Fig. 1. Evolution of friction coefficient with time. 
The average friction coefficient of the ionic liquids tested is shown in Table 4 . With less than three percent error in all cases, the differences were almost insignificant, in agreement with what is seen in Figure 1. In addition, the average wear volume is also displayed in Table 4, with an error value less than $7 \%$ in all cases. The expected trend was observed in this case: all ionic liquid mixtures outperformed the base oil, the improvement being greater with the increase in the $\left[\mathrm{P}_{66614}\right]\left[\mathrm{NTf}_{2}\right]$ concentration value.

Table 4. Mean friction and wear results.

\begin{tabular}{|c|c|c|c|c|}
\hline \multirow[b]{2}{*}{ Lubricant Sample } & \multicolumn{2}{|c|}{ Friction } & \multicolumn{2}{|l|}{ Wear } \\
\hline & Avg. $\mathrm{COF} \pm \sigma$ & $\begin{array}{l}\text { Error } \\
(\%)\end{array}$ & $\begin{array}{l}\text { Avg. wear volume } \pm \sigma \\
\left(\mu \mathrm{m}^{3} \times 10^{6}\right)\end{array}$ & $\begin{array}{c}\text { Error } \\
(\%)\end{array}$ \\
\hline A2 & $0.073 \pm 0.001$ & 1.4 & $6.0 \pm 0.4$ & 6.7 \\
\hline $\mathrm{A} 2+0.25 \%\left[\mathrm{P}_{66614}\right]\left[\mathrm{NTf}_{2}\right]$ & $0.073 \pm 0.001$ & 1.4 & $5.8 \pm 0.2$ & 3.4 \\
\hline $\mathrm{A} 2+0.5 \%\left[\mathrm{P}_{66614}\right]\left[\mathrm{NTf}_{2}\right]$ & $0.073 \pm 0.002$ & 2.7 & $5.7 \pm 0.4$ & 7.0 \\
\hline $\mathrm{A} 2+1 \%\left[\mathrm{P}_{66614}\right]\left[\mathrm{NTf}_{2}\right]$ & $0.072 \pm 0.002$ & 2.8 & $5.1 \pm 0.2$ & 3.9 \\
\hline
\end{tabular}

\subsection{Surface characterization}

In Fig. 2 can be seen the SEM micrographs taken from the wear scar for all samples tested. Although the $1 \mathrm{wt} \%$ blend slightly outperformed the neat base oil with regard wear reduction, the width of the wear scar measured at three different locations (center, right and left) resulting in similar values ranging from 707 to $796 \mu \mathrm{m}$ for all tests conducted. In addition, the SEM images showed that the worn surface suffered an adhesive wear mechanism in all cases. Finally, the EDS analysis mainly displayed the elements present in the steel, so these spectra have not been included and XPS analysis should be more help in determining the nature of the tribofilm formed by the IL-surface chemical interaction.

Regarding the XPS study, Fe, O, S, P and F were analyzed in every sample. Phosphorus and sulphur were not detected in the sample assayed with neat A2, as was to be expected; although the two elements could not be found in the other samples either. The absence of $\mathrm{P}$ can be explained if we bear in mind that phosphorus is only found in the cation and it has been reported that it is principally the anion which interacts with the surface [64]. 


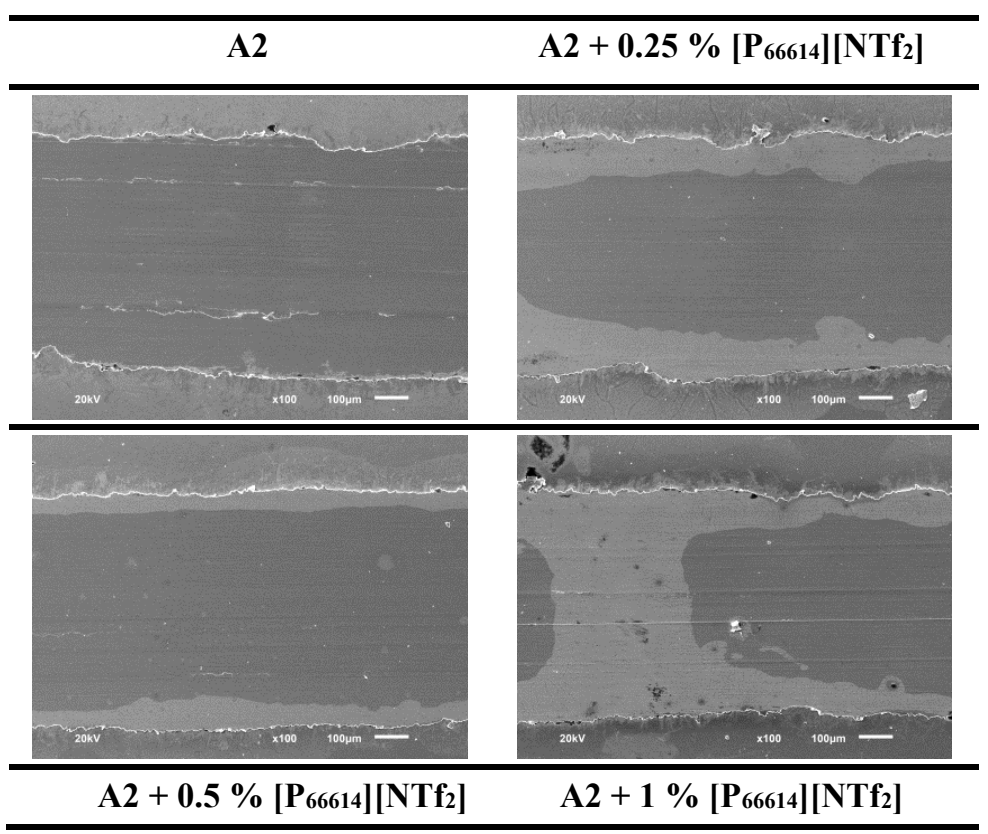

Fig. 2. SEM images (magnification: x100, scale length: $100 \mu \mathrm{m}$ ) from wear scar on disks.

The lack of sulphur on the surface is probably due to a problem related to the sensitivity of the measuring instrument to this element rather than to a real absence of it. This can be confirmed by checking the $\mathrm{F}_{1 \mathrm{~s}} /$ $\mathrm{Fe}_{2 \mathrm{p} 3 / 2}$ area ratio, which can be used as an estimation of the amount of anion interacting with the surface, ranging from 0.027 to 0.066 . Taking into account the $6: 1 \mathrm{~F} / \mathrm{S}$ atom ratio in the $\left[\mathrm{NTf}_{2}\right]$ anion, as well as the relative sensitivity of the XPS to the two elements, sulphur areas are expected to be $\sim 13 \%$ of those of fluorine, which actually makes $S$ undetectable. High resolution spectra of $F_{1 s}$ (Fig. 3a) reveal that this element does not appear in the sample lubricated with neat A2, as expected, but it is present in samples tested with $0.25 \%, 0.5 \%$ and $1.0 \%\left[\mathrm{P}_{66614}\right]\left[\mathrm{NTf}_{2}\right]$ at $688.3 \pm 0.1 \mathrm{eV}$, a value which corresponds to C-F bonds in $\left[\mathrm{NTf}_{2}\right]$ anion [65].
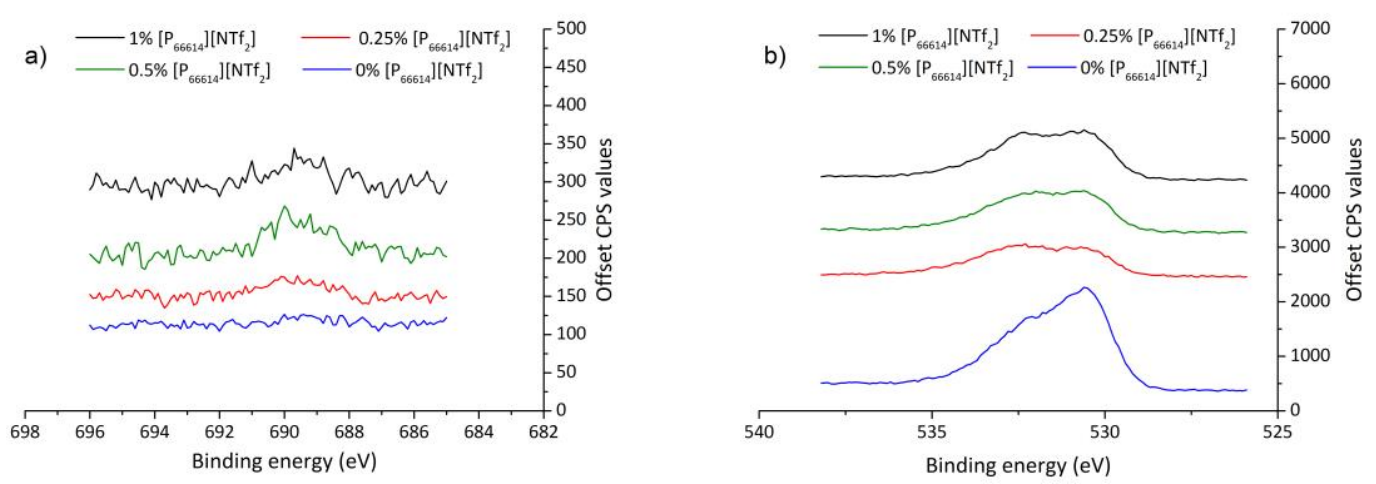

Fig. 3. F1s (a) and O1s (b) XPS high resolution spectra for samples lubricated with neat base oil, and $0.25 \%, 0.5 \%$ and $1 \%$ of $\left[\mathrm{P}_{66614}\right]\left[\mathrm{NTf}_{2}\right]$. 
With respect to the high-resolution analysis of iron, it is interesting to note that no differences in the chemical composition of this metal could be detected between the samples. The iron $\mathrm{Fe}_{2 \mathrm{p} 3 / 2}$ photoemission peak was fitted using four different curves, assuming the presence of $\mathrm{Fe}(\mathrm{III}), \mathrm{Fe}$ (II), $\mathrm{Fe}(0)$ and $\mathrm{FeOOH}$. A product of gaussian $(70 \%)$ and lorentzian (30\%) curves was used for every type of iron, although an asymmetry factor modelled as an exponential tail in the high binding energy section was used for Fe (III) and Fe (0), as described by Mangolini et al. [66]. The peaks were located at $706.1 \pm 0.2 \mathrm{eV}, 709.1 \pm 0.2$ $\mathrm{eV}, 710.4 \pm 0.3 \mathrm{eV}$ and $712.1 \pm 0.3 \mathrm{eV}$ which can be assigned respectively to $\mathrm{Fe}(0), \mathrm{Fe}$ (II), $\mathrm{Fe}$ (III) and $\mathrm{FeOOH}[66,67]$. Results of the fitting for Fe2p3/2 are summarized in Table 5 and Figure 4.

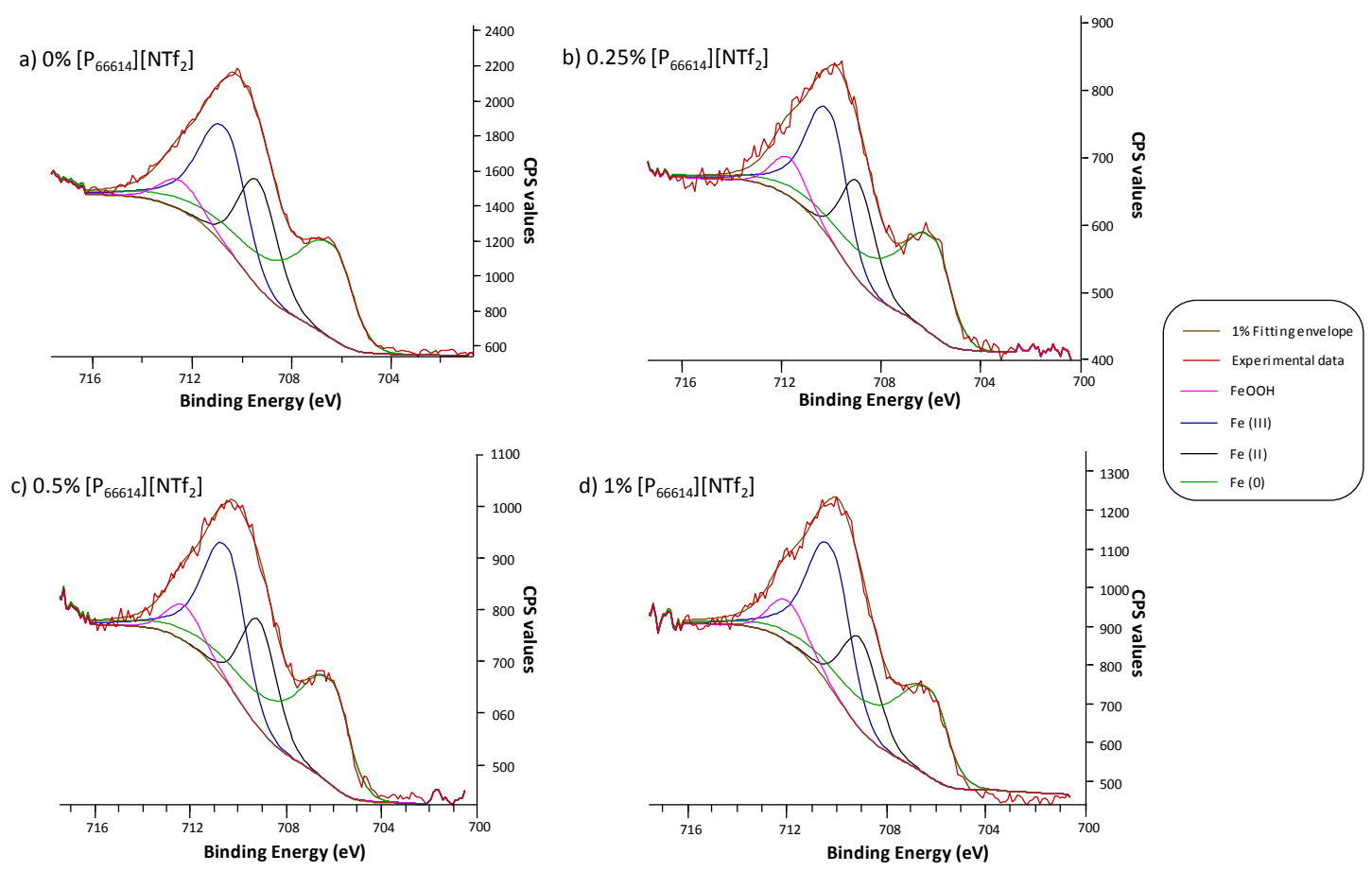

Fig. 4. Fe 2p3/2 XPS high-resolution spectra for samples lubricated with:

a) Neat base oil, b) $\mathrm{A} 2+0.25 \%\left[\mathrm{P}_{66614}\right]\left[\mathrm{NTf}_{2}\right]$, c) $\mathrm{A} 2+0.5 \%\left[\mathrm{P}_{66614}\right]\left[\mathrm{NTf}_{2}\right]$ and

d) $\mathrm{A} 2+1 \%\left[\mathrm{P}_{66614}\right]\left[\mathrm{NTf}_{2}\right]$.

The similarity of the chemical states of this element between the samples is consistent with that observed both in the coefficient of friction and the wear volume. Although the wear volume seems to decrease with increasing percentages of $\left[\mathrm{P}_{66614}\right]\left[\mathrm{NTf}_{2}\right]$, the change is not statistically significant and the reduction is so low that it cannot be seen in the iron ratios. 
On the other hand, Figure $3 \mathrm{~b}$ shows the O1s experimental peaks, which were fitted using three different curves: a first one at $532.7 \pm 0.3 \mathrm{eV}$ which can be assigned either to $\mathrm{NTf}_{2}$ or water, reported respectively at $532.4 \mathrm{eV}$ and $533.0 \mathrm{eV}[65,67]$, a second one at $531.1 \pm 0.1 \mathrm{eV}$ corresponding to hydroxides [66] and a third one at $529.4 \mathrm{eV} \pm 0.2 \mathrm{eV}$, probably from oxides [66].

Table 5. Results for the XPS Fe2p3/2 curve fitting. GL(30) represents a product of gaussian (70\%) and lorentzian $(30 \%)$ curve and $\mathrm{T}(\mathrm{x})$ indicates a tail in the peak with an assimetry factor of $\mathrm{x}$.

\begin{tabular}{|c|c|c|c|c|}
\hline \multirow{2}{*}{ Curve Fitting } & Fe (0) & $\mathrm{Fe}$ (II) & $\mathrm{Fe}$ (III) & FeOOH \\
\hline & GL (30) T (0.65) & GL (30) & GL (30) T (1.5) & GL (30) \\
\hline \multirow[t]{2}{*}{ A2 } & $706.4 \mathrm{eV}$ & $709.4 \mathrm{eV}$ & $710.7 \mathrm{eV}$ & $712.5 \mathrm{eV}$ \\
\hline & $(40 \%)$ & $(22 \%)$ & $(32 \%)$ & $(6 \%)$ \\
\hline \multirow[t]{2}{*}{$\mathrm{A} 2+0.25 \%\left[\mathrm{P}_{66614}\right]\left[\mathrm{NTf}_{2}\right]$} & $705.9 \mathrm{eV}$ & $708.9 \mathrm{eV}$ & $710.1 \mathrm{eV}$ & $711.7 \mathrm{eV}$ \\
\hline & $(40 \%)$ & $(20 \%)$ & $(33 \%)$ & $(8 \%)$ \\
\hline \multirow[t]{2}{*}{$\mathrm{A} 2+0.5 \%\left[\mathrm{P}_{66614}\right]\left[\mathrm{NTf}_{2}\right]$} & $706.1 \mathrm{eV}$ & $709.1 \mathrm{eV}$ & $710.4 \mathrm{eV}$ & $712.3 \mathrm{eV}$ \\
\hline & $(40 \%)$ & $(20 \%)$ & $(33 \%)$ & $(7 \%)$ \\
\hline \multirow[t]{2}{*}{$\mathrm{A} 2+1 \%\left[\mathrm{P}_{66614}\right]\left[\mathrm{NTf}_{2}\right]$} & $706.2 \mathrm{eV}$ & $709.1 \mathrm{eV}$ & $710.2 \mathrm{eV}$ & $712.0 \mathrm{eV}$ \\
\hline & $(36 \%)$ & $(18 \%)$ & $(37 \%)$ & $(9 \%)$ \\
\hline
\end{tabular}

* Number in brackets indicates the contribution of that peak to the global curve.

Table 6 shows the percentage of oxygen from every source as well as the oxygen / iron ratio. Although the content of $\mathrm{O}$ from $\mathrm{NTf}_{2}$ or water seems to be constant or even decreases with IL, it must be remembered that the percentages shown are relative to the total amount of $\mathrm{O}$. Considering the $\mathrm{O} / \mathrm{Fe}$ ratio as well, the sample with $\mathrm{A} 2 \mathrm{has}$ the lowest $\mathrm{O} 1 \mathrm{~s}$ value at $532.7 \mathrm{eV}$.

Table 6. O1s and $\mathrm{O} / \mathrm{Fe}$ ratio.

\begin{tabular}{|c|c|c|c|c|}
\hline \multirow[b]{2}{*}{ Sample } & $532.7(\mathrm{eV})$ & $529.4(\mathrm{eV})$ & $531.1(\mathrm{eV})$ & \multirow[b]{2}{*}{$\mathrm{O} / \mathrm{Fe}$} \\
\hline & $\begin{array}{c}\mathrm{NTf}_{2} / \text { water } \\
(\%)\end{array}$ & $\begin{array}{c}\text { Iron oxides } \\
(\%)\end{array}$ & $\begin{array}{c}\text { Hydroxides } \\
(\%)\end{array}$ & \\
\hline A2 & 12.1 & 55.6 & 32.5 & 1.17 \\
\hline $\mathrm{A} 2+0.25 \%\left[\mathrm{P}_{66614}\right]\left[\mathrm{NTf}_{2}\right]$ & 12.1 & 43.2 & 44.7 & 2.09 \\
\hline $\mathrm{A} 2+0.5 \%\left[\mathrm{P}_{66614}\right]\left[\mathrm{NTf}_{2}\right]$ & 13.4 & 46.4 & 40.3 & 1.65 \\
\hline $\mathrm{A} 2+1 \%\left[\mathrm{P}_{66614}\right]\left[\mathrm{NTf}_{2}\right]$ & 9.8 & 47.9 & 42.4 & 1.69 \\
\hline
\end{tabular}

Higher values for the $\mathrm{O} / \mathrm{Fe}$ ratio were found for samples containing $\left[\mathrm{P}_{66614}\right]\left[\mathrm{NTf}_{2}\right]$ (2.089 for $0.25 \%$, 1.654 for $0.5 \%$ and 1.686 for $1 \%$ ) than for the neat base oil sample (1.169), as a consequence of small 
chemical variations on the surface detected by XPS due to the presence of $\left[\mathrm{NTf}_{2}\right]$ anion. In previous work $[35,60]$ differences in these ratios (oxihydroxydes/oxides, $\mathrm{Fe} / \mathrm{O}$ ) were related to the wear volume. However, in this case, such changes in $\mathrm{Fe} / \mathrm{O}$ do not seem to correspond to tribological variations between samples with [ $\left.\mathrm{NTf}_{2}\right]$, which suggests the need for further analysis.

The use of a base oil (an ester in this case) with polar nature could lead to a competition for the metallic surface between the ionic liquid and the base oil in order to form physical bonds. This competition can influence negatively on the expected tribological improvement from the use of the ionic liquid as an additive in comparison with the base oil. Thus, in this work a noteworthy difference in tribological behavior (wear reduction) was found only for the mixture with highest concentration of ionic liquid.

The influence of polarity has been demonstrated for mixtures formed by a low polarity base oil (polyalphaolefins or mineral oils), as the main component, and a polar compound (ester), resulting in improved tribological behavior (friction and wear) under both mixed and boundary lubrication conditions [68-69]. This fact was also proved with mixtures of a non-polar oil (mineral oil or polyalphaolefin) and ionic liquids used separately as an additive, even at low concentrations, in a steel-steel contact, resulting in better friction and wear performance of the mixtures with regard to the neat base oil $[35,53,60,70-72]$. Also, that tribological improvement by using ionic liquids as an additive in non-polar oils was found in pairs with coated surfaces [22-23, 73-74].

\section{Conclusions}

The tribological behavior of a novel $\left[\mathrm{NTf}_{2}\right]$ anion-based ionic liquid was studied as an additive to a diester oil in three different concentrations $(0.25,0.5$ and $1 \mathrm{wt} \%)$ in steel-steel contact using a reciprocating ball-on-disk configuration. From the results obtained, the following conclusions can be drawn:

- Solubility tests found that a saturated solution of $\left[\mathrm{P}_{66614}\right]\left[\mathrm{NTf}_{2}\right]$ in the base oil contains around $30 \mathrm{wt} \%$ of IL, allowing its use as a lubricant additive. In addition, the sample with the highest concentration (1 wt \%) used does not show corrosion activity.

- All IL mixtures showed similar friction results to the base oil, but only the mixture with highest IL concentration (1 wt\%) showed appreciable wear reduction in comparison with the neat base oil. These results could be related to the competition of the base oil and the ionic liquid for the 
metallic surface due to their polar nature, which worsens the expected improved tribological behavior of the IL-containing mixtures.

- The similarity of the chemical states of Fe between the samples when observed by XPS is consistent with the similar friction results obtained. The slight wear reduction observed with the addition of ionic liquid could be explained by the small chemical variations in the surface that were identified by XPS analysis.

\section{Acknowledgements}

The authors would like to thank to the Ministry of Economy and Competitiveness (Spain) and FICYT (Foundation for the Promotion in Asturias of the Applied Scientific Research and Technology) for supporting the research projects STARLUBE (DPI2013-48348-C2-1-R), GRUPIN14-023 and MINECO16-MAT2015-66747-R, within whose framework this research was conducted. The authors would also like to thank CRODA S.A. for kindly providing the base oil used for the development of this research. Finally, the Scientific-Technical Services at the University of Oviedo are also acknowledged.

\section{References}

1. Fraser, K.J., MacFarlane, D.R.: Phosphonium-based ionic liquids: An overview. Aust. J. Chem. 62, 309-321 (2009).

2. Ye, C., Liu, W., Chen, Y., Yu, L.: Room-temperature ionic liquids: a novel versatile lubricant. Chem. Commun. 21, 2244-2245 (2001).

3. Minami, I.: Ionic liquids in tribology. Molecules. 14, 2286-2305 (2009).

4. Bermúdez, M.D., Jiménez, A.E., Sanes, J., Carrión, F.J.: Ionic liquids as advanced lubricant fluids. Molecules. 14, 2888-2908 (2009).

5. Palacio, M., Bhushan, B.: A review of ionic liquids for green molecular lubrication in nanotechnology. Tribol. Lett. 40, 247-268 (2010).

6. Somers, A., Howlett, P., MacFarlane, D., Forsyth, M.: A Review of Ionic Liquid Lubricants. Lubricants. 1, 3-21 (2013).

7. Zhou, F., Liang, Y., Liu, W.: Ionic liquid lubricants: designed chemistry for engineering applications. Chem. Soc. Rev. 38, 2590-2599 (2009).

8. Rensselar, J. Van: Unleashing the potential of ionic liquids. Tribol. Lubr. Technol. April, (2010). 
9. Liu, W., Ye, C., Gong, Q., Wang, H., Wang, P.: Tribological performance of room-temperature ionic liquids as lubricant. Tribol. Lett. 13, 81-85 (2002).

10. Chen, Y.M., Zeng, Z.X., Yang, S.R., Zhang, J.Y.: The tribological performance of BCN films under ionic liquids lubrication. Diam. Relat. Mater. 18, 20-26 (2009).

11. Sanes, J., Carrión, F.J., Bermúdez, M.D., Martínez-Nicolás, G.: Ionic liquids as lubricants of polystyrene and polyamide 6-steel contacts. Preparation and properties of new polymer-ionic liquid dispersions. Tribol. Lett. 21, 121-133 (2006).

12. Kamimura, H., Kubo, T., Minami, I., Mori, S.: Effect and mechanism of additives for ionic liquids as new lubricants. Tribol. Int. 40, 620-625 (2007).

13. Qu, J., Truhan, J.J., Dai, S., Luo, H., Blau, P.J.: Ionic liquids with ammonium cations as lubricants or additives. Tribol. Lett. 22, 207-214 (2006).

14. Jiménez, A. E., Bermúdez, M.D., Iglesias, P., Carrión, F.J., Martínez-Nicolás, G.: 1-N-alkyl -3methylimidazolium ionic liquids as neat lubricants and lubricant additives in steel-aluminium contacts. Wear. 260, 766-782 (2006).

15. Battez, A. H., González, R., Viesca, J.L., Blanco, D., Asedegbega, E., Osorio, A.: Tribological behaviour of two imidazolium ionic liquids as lubricant additives for steel/steel contacts. Wear. 266, 1224-1228 (2009).

16. Phillips, B.S., John, G., Zabinski, J.S.: Surface chemistry of fluorine containing ionic liquids on steel substrates at elevated temperature using Mössbauer spectroscopy. Tribol. Lett. 26, 85-91 (2007).

17. Mu, Z., Liu, W., Zhang, S., Zhou, F.: Functional room-temperature ionic liquids as lubricants for an aluminum-on-steel system. Chem. Lett. 33 (5), 524-525 (2004).

18. Torimoto, T., Tsuda, T., Okazaki, K.I., Kuwabata, S.: New frontiers in materials science opened by ionic liquids. Adv. Mater. 22, 1196-1221 (2010).

19. García, A., González, R., Hernández Battez, A., Viesca, J.L., Monge, R., Fernández-González, A., Hadfield, M.: Ionic liquids as a neat lubricant applied to steel-steel contacts. Tribol. Int. 72, 42-50 (2014).

20. Uerdingen, M., Treber, C., Balser, M., Schmitt, G., Werner, C.: Corrosion behaviour of ionic liquids. Green Chem. 7, 321 (2005). 
21. González, R., Hernández Battez, A., Blanco, D., Viesca, J.L., Fernández-González, A.: Lubrication of TiN, CrN and DLC PVD coatings with 1-butyl-1- methylpyrrolidinium tris(pentafluoroethyl)trifluorophosphate. Tribol. Lett. 40, 269-277 (2010).

22. Blanco, D., González, R., Hernández Battez, A., Viesca, J.L., Fernández-Gonzlez, A.: Use of ethyldimethyl-2-methoxyethylammonium tris(pentafluoroethyl) trifluorophosphate as base oil additive in the lubrication of TiN PVD coating. Tribol. Int. 44, 645-650 (2011).

23. Blanco, D., Battez, A. H., Viesca, J.L., González, R., Fernández-González, A.: Lubrication of CrN coating with ethyl-dimethyl-2-methoxyethylammonium tris(pentafluoroethyl)trifluorophosphate ionic liquid as additive to PAO 6. Tribol. Lett. 41, 295-302 (2011).

24. Viesca, J.L., García, A., Hernández Battez, A., González, R., Monge, R., Fernández-González, A., Hadfield, M.: FAP- anion ionic liquids used in the lubrication of a steel-steel contact. Tribol. Lett. $52,431-437(2013)$

25. Minami, I., Kita, M., Kubo, T., Nanao, H., Mori, S.: The tribological properties of ionic liquids composed of trifluorotris(pentafluoroethyl) phosphate as a hydrophobic anion. Tribol. Lett. 30, 215-223 (2008).

26. Otero, I., López, E.R., Reichelt, M., Fernández, J.: Friction and anti-wear properties of two tris(pentafluoroethyl) trifluorophosphate ionic liquids as neat lubricants. Tribol. Int. 70, 104-111 (2014).

27. Viesca, J.L., Battez, A. H., González, R., Reddyhoff, T., Pérez, A. T., Spikes, H. A.: Assessing boundary film formation of lubricant additivised with 1-hexyl-3-methylimidazolium tetrafluoroborate using ECR as qualitative indicator. Wear. 269, 112-117 (2010).

28. Hernández Battez, A., González, R., Viesca, J.L., Fernández-González, A., Hadfield, M.: Lubrication of PVD coatings with ethyl-dimethyl-2-methoxyethylammonium tris(pentafluoroethyl)trifluorophosphate. Tribol. Int. 58, 71-78 (2013).

29. Somers, A.E., Biddulph, S.M., Howlett, P.C., Sun, J., MacFarlane, D.R., Forsyth, M.: A comparison of phosphorus and fluorine containing IL lubricants for steel on aluminium. Phys. Chem. Chem. Phys. 14, 8224 (2012).

30. Viesca, J.-L., Anand, M., Blanco, D., Fernández-González, A., García, A., Hadfield, M.: Tribological Behaviour of PVD Coatings Lubricated with a FAP- Anion-Based Ionic Liquid Used as an Additive. Lubricants. 4, 8 (2016). 
31. Kheireddin, B. A., Lu, W., Chen, I.C., Akbulut, M.: Inorganic nanoparticle-based ionic liquid lubricants. Wear. 303, 185-190 (2013).

32. Pisarova, L., Gabler, C., Dörr, N., Pittenauer, E., Allmaier, G.: Thermo-oxidative stability and corrosion properties of ammonium based ionic liquids. Tribol. Int. 46, 73-83 (2012).

33. Cai, M., Liang, Y., Yao, M., Xia, Y., Zhou, F., Liu, W.: Imidazolium ionic liquids as antiwear and antioxidant additive in poly(ethylene glycol) for steel/steel contacts. ACS Appl. Mater. Interfaces. 2, 870-876 (2010).

34. Gabler, C., Dörr, N., Allmaier, G.: Influence of cationic moieties on the tribolayer constitution shown for bis(trifluoromethylsulfonyl)imide based ionic liquids studied by X-ray photoelectron spectroscopy. Tribol. Int. 80, 90-97 (2014).

35. Monge, R., González, R., Hernández Battez, A., Fernández-González, A., Viesca, J.L., García, A., Hadfield, M.: Ionic liquids as an additive in fully formulated wind turbine gearbox oils. Wear. 328$329,50-63(2015)$.

36. Somers, A.E., Howlett, P.C., Sun, J., MacFarlane, D.R., Forsyth, M.: Transition in wear performance for ionic liquid lubricants under increasing load. Tribol. Lett. 40, 279-284 (2010).

37. Murakami, T., Kaneda, K., Nakano, M., Korenaga, A., Mano, H., Sasaki, S.: Tribological properties of Fe7Mo6-based alloy under two ionic liquid lubrications. Tribol. Int. 41, 1083-1089 (2008).

38. Bandeira, P., Monteiro, J., Baptista, A.M., Magalhães, F.D.: Tribological performance of PTFEbased coating modified with microencapsulated $[\mathrm{HMIM}]\left[\mathrm{NTf}_{2}\right]$ ionic liquid. Tribol. Lett. 59, (2015).

39. Somers, A.E., Khemchandani, B., Howlett, P.C., Sun, J., Macfarlane, D.R., Forsyth, M.: Ionic liquids as antiwear additives in base oils: Influence of structure on miscibility and antiwear performance for steel on aluminum. ACS Appl. Mater. Interfaces. 5, 11544-11553 (2013).

40. Minami, I., Inada, T., Sasaki, R., Nanao, H.: Tribo-Chemistry of Phosphonium-Derived Ionic Liquids. Tribol. Lett. 40, 225-235 (2010).

41. Qu, J., Blau, P.J., Dai, S., Luo, H., Meyer, H.M.: Ionic Liquids as Novel Lubricants and Additives for Diesel Engine Applications. Tribol. Lett. 35, 181-189 (2009).

42. Mistry, K., Fox, M.F., Priest, M.J.: Lubrication of an Electroplated Nickel Matrix Silicon Carbide Coated Eutectic Aluminium-Silicon Alloy Automotive CylinderBore with an Ionic Liquid as a Lubricant Additive. Eng. Tribol. 223, 563-569 (2009). 
43. Schneider, A., Brenner, J., Tomastik, C., Franek, F.: Capacity of selected ionic liquids as alternative EP/AW. Lubr. Sci. 22, 215-223 (2010).

44. Jiménez, A.E., Bermúdez, M.D.: Imidazolium ionic liquids as additives of the synthetic ester propylene glycol dioleate in aluminium-steel lubrication. Wear. 265, 787-798 (2008).

45. Hernández Battez, A., Bartolomé, M., Blanco, D., Viesca, J.L., Fernández-González, A., González, R.: Phosphonium cation-based ionic liquids as neat lubricants: Physicochemical and tribological performance. Tribol. Int. 95, 118-131 (2016).

46. Espinosa, T., Sanes, J., Bermúdez, M.-D.: New alkylether-thiazolium room-temperature ionic liquid lubricants. Surface interactions and tribological performance. ACS Appl. Mater. Interfaces. 8, 18631-18639 (2016).

47. Mahrova, M., Pagano, F., Pejakovic, V., Valea, A., Kalin, M., Igartua, A, Tojo, E.: Pyridinium based dicationic ionic liquids as base lubricants or lubricant additives. Tribol. Int. 82, 245-254 (2015).

48. Fan, M., Zhang, C., Guo, Y., Zhang, R., Lin, L., Yang, D., Zhou, F., Liu, W.: An Investigation on the Friction and Wear Properties of Perfluorooctane Sulfonate Ionic Liquids. Tribol. Lett. 63, 11 (2016).

49. Otero, I., López, E.R., Reichelt, M., Villanueva, M., Salgado, J., Fernández, J.: Ionic liquids based on phosphonium cations as neat lubricants or lubricant additives for a steel/steel contact. ACS Appl. Mater. Interfaces. 6, 13115-28 (2014).

50. Wu, J., Lu, X., Feng, X., Shi, Y.: Halogen-free ionic liquids as excellent lubricants for PEEKstainless steel contacts at elevated temperatures. Tribol. Int. 104, 1-9 (2016).

51. Zhang, S., Hu, L., Qiao, D., Feng, D., Wang, H.: Vacuum tribological performance of phosphonium-based ionic liquids as lubricants and lubricant additives of multialkylated cyclopentanes. Tribol. Int. 66, 289-295 (2013).

52. Nainaparampil, J.J., Eapen, K.C., Sanders, J.H., Voevodin, A. A.: Ionic-liquid lubrication of sliding MEMS contacts: Comparison of AFM liquid cell and device-level tests. J. Microelectromechanical Syst. 16, 836-843 (2007).

53. Anand, M., Hadfield, M., Viesca, J.L., Thomas, B., Hernández Battez, A., Austen, S.: Ionic liquids as tribological performance improving additive for in-service and used fully-formulated diesel engine lubricants. Wear. 334-335, 67-74 (2015). 
54. Yu, B., Bansal, D.G., Qu, J., Sun, X., Luo, H., Dai, S., Blau, P.J., Bunting, B.G., Mordukhovich, G., Smolenski, D.J.: Oil-miscible and non-corrosive phosphonium-based ionic liquids as candidate lubricant additives. Wear. 289, 58-64 (2012).

55. Qu, J., Luo, H., Chi, M., Ma, C., Blau, P.J., Dai, S., Viola, M.B.: Comparison of an oil-miscible ionic liquid and ZDDP as a lubricant anti-wear additive. Tribol. Int. 71, 88-97 (2014).

56. Barnhill, W.C., Qu, J., Luo, H., Meyer, H.M., Ma, C., Chi, M., Papke, B.L.: PhosphoniumOrganophosphate Ionic Liquids as Lubricant Additives: Effects of Cation Structure on Physicochemical and Tribological Characteristics. ACS Appl. Mater. Interfaces. 6, 22585-22593 (2014).

57. Totolin, V., Minami, I., Gabler, C., Brenner, J., Dörr, N.: Lubrication mechanism of phosphonium phosphate ionic liquid additive in alkylborane-imidazole complexes. Tribol. Lett. 53, 421-432 (2014).

58. Khemchandani, B., Somers, A., Howlett, P., Jaiswal, A. K., Sayanna, E., Forsyth, M.: A biocompatible ionic liquid as an antiwear additive for biodegradable lubricants. Tribol. Int. 77, $171-177$ (2014).

59. Qu, J., Barnhill, W.C., Luo, H., Meyer, H.M., Leonard, D.N., Landauer, A.K., Kheireddin, B., Gao, H., Papke, B.L., Dai, S.: Synergistic Effects between Phosphonium-Alkylphosphate Ionic Liquids and Zinc Dialkyldithiophosphate (ZDDP) as Lubricant Additives. Adv. Mater. 27, 4767-4774 (2015).

60. González, R., Bartolomé, M., Blanco, D., Viesca, J.L., Fernández-González, A., Battez, A.H.: Effectiveness of phosphonium cation-based ionic liquids as lubricant additive. Tribol. Int. 98, 8293 (2016).

61. Fredriksson, W., Edström, K.: XPS study of duplex stainless steel as a possible current collector in a Li-ion battery. Electrochim. Acta. 79, 82-94 (2012).

62. Gorzalski, A.S., Donley, C., Coronell, O.: Elemental composition of membrane foulant layers using EDS, XPS, and RBS. J. Memb. Sci. 522, 31-44 (2017).

63. Prakash, A., Sundaram, K.B.: Optical and XPS studies of BCN thin films by co-sputtering of B4C and BN targets. Appl. Surf. Sci. 396, 484-491 (2017). 
64. Sharma, V., Gabler, C., Doerr, N., Aswath, P.B.: Mechanism of tribofilm formation with P and S containing ionic liquids. Tribol. Int. 92, 353-364 (2015).

65. Beattie, D.A., Harmer-Bassell, S.L., Ho, T.T.M., Krasowska, M., Ralston, J., Sellaperumage, P.M.F., Wąsik, P.: Spectroscopic study of ionic liquids adsorption from solution onto gold. Phys. Chem. Chem. Phys. 17, 4199-4209 (2015).

66. Mangolini, F., Rossi, A., Spencer, N.D.: Influence of metallic and oxidized iron/steel on the reactivity of triphenyl phosphorothionate in oil solution. Tribol. Int. 44, 670-683 (2011).

67. Mayer, T.: Black spots on carbon steel after contact to lubricating oil with extreme pressure additives: an XPS study. Appl. Surf. Sci. 179, 257-262 (2001).

68. Fernández Rico, J.E., Hernández Battez, A., García Cuervo, D.: Wear prevention characteristics of binary oil mixtures. Wear 253:827-31 (2002).

69. Cambiella, A., Benito, J.M., Pazos, C., Coca, J., Hernández, A., Fernández, J.E.: Formulation of emulsifiable cutting fluids and extreme pressure behaviour. J Mater Process Technol 184:139-45 (2007).

70. Hernández Battez, A., Fernandes, C.M.C.G., Martins, R.C., Bartolomé, M., González, R., Seabra, J.H.O.: Two phosphonium cation-based ionic liquids used as lubricant additive. Tribol. Int. 107, 233-239 (2017).

71. Hernández Battez, A., Fernandes, C.M.C.G., Martins, R.C., Graça, B.M., Anand, M., Blanco, D., Seabra, J.H.O.: Two phosphonium cation-based ionic liquids used as lubricant additive. Part II: Tribofilm analysis and friction torque loss in cylindrical roller thrust bearings at constant temperature. Tribol. Int. 109, 496-504 (2017).

72. Fernandes, C.M.C.G., Battez, A.H., González, R., Monge, R., Viesca, J.L., García, A., Martins, R.C., Seabra, J.H.O.: Torque loss and wear of FZG gears lubricated with wind turbine gear oils using an ionic liquid as additive. Tribol. Int. 90, 306-314 (2015).

73. González, R., Battez, A.H., Viesca, J.L., Higuera-Garrido, A., Fernández-González, A.: Lubrication of DLC Coatings with Two Tris(pentafluoroethyl)trifluorophosphate Anion-Based Ionic Liquids. Tribology Transactions 56, 887-895 (2013).

74. Hernández Battez, A., González, R., Viesca, J.L., Fernández-González, A., Hadfield, M.: Lubrication of PVD coatings with ethyl-dimethyl-2-methoxyethylammonium tris(pentafluoroethyl)trifluorophosphate. Tribol. Int. 58, 71-78 (2013). 